\title{
CORRECTION
}

\section{Correction to: strength of single-crystal orthopyroxene under lithospheric conditions}

\author{
Tomohiro Ohuchi $^{1,2} \cdot$ Shun-ichiro Karato ${ }^{1} \cdot$ Kiyoshi Fujino $^{2}$
}

Published online: 2 April 2018

(c) Springer-Verlag GmbH Germany, part of Springer Nature 2018

\section{Correction to: Contrib Mineral Petrol (2011) 161:961-975 https://doi.org/10.1007/s00410-010-0574-3}

In the version of the article originally published, Eqs. (6), (7b), and (7c) were shown incorrectly. The corrected equations are the following:

$$
\begin{aligned}
& \dot{\gamma}=B \cdot \exp \left\{\frac{-Q_{l}}{R T}\left[1-\left(\tau / \tau_{p}\right)^{p}\right]^{q}\right\} \\
& \dot{\gamma}=10^{14.0 \pm 2.9} \times \exp \left\{\frac{-525 \pm 98 \mathrm{~kJ} \mathrm{~mol}^{-1}}{R T}[1-\tau / 3073 \pm 546 \mathrm{MPa}]^{2}\right\} \\
& \dot{\gamma}=10^{10.7 \pm 2.3} \times \exp \left\{\frac{-560 \pm 110 \mathrm{~kJ} \mathrm{~mol}^{-1}}{R T}\left[1-(\tau / 3559 \pm 842 \mathrm{MPa})^{0.5}\right]^{1.5}\right\} .
\end{aligned}
$$

These corrections do not affect any of the results or other expressions in the paper. We are grateful to Dr. Yanbin Wang for pointing out the above errors. 